\title{
The Effects of Host Diversity and Other Management Components on Epidemics of Potato Late Blight in the Humid Highland Tropics
}

\author{
K. A. Garrett, R. J. Nelson, C. C. Mundt, G. Chacón, R. E. Jaramillo, and G. A. Forbes
}

First, fourth, fifth, and sixth authors: Centro Internacional de la Papa, Casilla 17-21-1977, Quito, Ecuador; second author: Centro Internacional de la Papa, Apartado 1558, Lima 12, Peru; and third author: Department of Botany and Plant Pathology, 2082 Cordley Hall, Oregon State University, Corvallis 97331.

Current address of K. A. Garrett: Department of Plant Pathology, Kansas State University, Manhattan 66506. Accepted for publication 8 June 2001.

\begin{abstract}
Garrett, K. A., Nelson, R. J., Mundt, C. C., Chacón, G., Jaramillo, R. E., and Forbes, G. A. 2001. The effects of host diversity and other management components on epidemics of potato late blight in the humid highland tropics. Phytopathology 91:993-1000.

A field study at three highland sites near Quito, Ecuador, was conducted to determine whether host-diversity effects on potato late blight would be as important as recently found in studies conducted in temperate areas. We compared three potato mixtures and use of mixtures in combination with different planting densities and two fungicide regimes. Treatment comparisons were made by absolute and relative measures of host-diversity effects and incorporating a truncated area under the disease progress curve as a means of standardizing comparisons across sites. Potato-faba intercrops consisting of only $10 \%$ potato provided an estimate of the effects of dilution of susceptible host tissue. Host-diversity effects
\end{abstract}

ABSTRACT

There is evidence for a potentially important effect of host diversity on potato late blight in temperate regions such as France (D. Andrivon, personal communication) and the United States (11). However, results from these studies cannot be directly extrapolated to the humid highland tropics where the epidemiology of late blight may be very different. One likely difference between tropical and temperate systems is the level of inoculum that will arrive at newly planted fields. Year round potato production and the continuous presence of late blight have been described by researchers working in the highland tropics $(13,19)$, and fungicides are used regularly throughout the year (4). This is in contrast to Europe and North America where blight epidemics must begin again each growing season. Although inoculum dynamics for temperate and tropical systems have not been directly compared, indirect evidence from other studies corroborates the hypothesis that the two systems are quite different. Studies of the minimal plot size required for measuring late blight resistance in potato genotypes in Quito, Ecuador, suggests that rows of five plants are as effective as larger plots isolated by a nonhost (22). High levels of aerial inoculum in the Quito area probably made inoculum supplied by neighboring plots relatively unimportant.

Late blight is a major constraint to potato production in the Andean highlands. Although farmers sometimes employ moderate levels of host plant resistance, the primary control strategy has been to spray with fungicides. Often the disease is not managed successfully and losses are heavy. Use of more resistant cultivars and better deployment of host resistance could reduce losses and

Corresponding author: K. A. Garrett; E-mail address: kgarrett@ksu.edu

Publication no. P-2001-0803-01R

(C) 2001 The American Phytopathological Society were very different across study sites, with a large host-diversity effect for reduced disease only at the site most distant from commercial potato production. Planting density had little influence on host-diversity effects or on late blight in single-genotype stands. Fungicide use in combination with potato mixtures enhanced a host-diversity effect for reduced late blight. Potato-faba intercrops produced only a small decrease in potato late blight. Effects of host diversity on yield were variable, with the greatest increase in yield for mixtures treated with fungicides at the site most distant from commercial potato production. The effects of host diversity on late blight severity may be less consistent in the tropical highlands than in the temperate zone, but can contribute to integrated disease management.

Additional keywords: cultivar mixtures, genotype diversity, intercropping, Phytophthora infestans, primary inoculum, Solanum tuberosum, Vicia faba.

dependence on chemical control. Mixtures of potato cultivars and intercropping of potatoes with legumes are traditional cropping systems in the Andes (21). There are many motives for the use of mixtures and intercropping, including an appreciation for the maintenance of genetic resources (P. Winters, personal communication). We are unaware, however, of information about the role that cultivar mixtures or intercropping may play in managing late blight in the highland tropics. Therefore, it would be very useful to quantify the effect of host diversity on late blight epidemics as part of an effort to optimize deployment of host resistance.

In the study reported here, we estimated the host-diversity effect for three potato genotype mixtures at three sites in the humid highland tropics of Ecuador. Potato-faba intercrops provided another estimate of the effects of crop diversity. We also examined how two other factors affected late blight and interacted with the effect of host diversity. First, we manipulated the planting density of potatoes, both to determine how this influenced hostdiversity effects and to make our results more directly comparable to results obtained in the United States (11), where higher planting densities are typical. The influence of host density on host-diversity effects in wheat stripe rust was important (12), and we compare results for the two systems. Second, we applied fungicides on two different schedules in potato mixtures and in corresponding single-genotype plots. If fungicide applications are successful in slowing epidemics that would have led to the rapid destruction of plants, the slower epidemics would include more time for more generations of pathogen increase and this would be expected to increase the effects of host diversity $(10,17)$. Maintaining this set of current and potential integrated pest management (IPM) components and their combinations at three sites enabled us to make a general comparison of their relative contributions to potato late blight management. 


\section{MATERIALS AND METHODS}

Experimental sites and plot design. Experiments were carried out at one site during the 1996-97 season and at three sites during the 1997-98 season (Table 1). The first site, at Estación Santa Catalina (ESC), was surrounded by other infected potato (Solanum tuberosum) fields, with some fields as near as $500 \mathrm{~m}$, in an area of intense potato production. The second site, at Instituto Andino Superior de Agropecuaria (IASA), was in a humid valley floor about $5 \mathrm{~km}$ from the nearest potatoes, which grew on the slopes above the valley. The third site, at Centro Académico Docente Experimental La Tola (CADET), was located in a valley that was considerably drier and warmer than the other sites and about $15 \mathrm{~km}$ from other potato fields. Plots were arranged in a randomized complete block design with four blocks at each site. The plots were $5 \times 5 \mathrm{~m}^{2}$ in area including a $0.5 \mathrm{~m}$ deep perimeter of oats (Avena sativa) around each plot. Plots of potatoes were alternated in a checkerboard pattern with buffer plots $\left(5 \times 5 \mathrm{~m}^{2}\right)$ planted only with oats. Each plot consisted of four rows of potatoes, with rows spaced $1.1 \mathrm{~m}$ apart (1.2 $\mathrm{m}$ apart at site IASA98) and plants $0.4 \mathrm{~m}$ apart within the row for a total of 40 plants per plot in standard density plots. At ESC97, one plant in the center square meter of each plot was randomly selected for inoculation with a suspension of a local isolate of Phytophthora infestans. However, the background of infection, apparently from outside inoculum, was so high that the inoculated plant could not be distinguished from others 1 week later. The other sites were left to natural infection.

Cultivar mixtures, faba intercropping, density, and fungicide treatments. Cultivars selected for mixtures were chosen for measurably different levels of resistance to late blight and were also included in the study in single-genotype stands (Table 2). In 1996-97, the positions of genotypes were randomized; and in 1997-98, the positions were systematically determined, maximizing the distance between individuals of the same cultivar. Intercrop plots contained 1/10 (four plants) potato and 9/10 (36 plants) of a local faba bean cultivar (Huagra in 1996-97; INIAP-Quitumbe in 1997-98). Only one potato cultivar was present within each intercrop plot: Santa Catalina, Gabriela, Cecilia, or Uvilla (Table 2, treatments 8 to 11). In 1997-98, a treatment with the 3/4 'Santa Catalina' and 1/4 'Uvilla' mixture planted at twice the standard density, or 80 plants per plot, was added (treatment 14). For testing host-diversity effects at this higher density, additional treatments of single-genotype stands of cvs. Santa Catalina and Uvilla at high density were included (treatments 12 and 13). In order to allow a suitable canopy size for study prior to the beginning of the late blight epidemic, all plots at each site were treated with a protectant fungicide until shortly before disease evaluation began. To test for interactions between fungicide applications and genotype mixing, fungicide treatments throughout the season were added for the 3/4 'Santa Catalina' and 1/4 'Uvilla' mixture in 1997-98, as outlined in Table 2.

Disease assessment and data analysis. The percentage of blighted leaf and stem tissue was estimated visually on the dates indicated in Table 1. For intercrop plots, the percentage of blighted tissue was estimated based only on the potato plants, ignoring the late blight-immune fabas.

Calculation of area under disease progress curve (AUDPC), relative mixture response, and truncated AUDPC. AUDPC,

TABLE 1. Research sites near Quito, Ecuador, for a study of the effects of host diversity and other integrated pest management components for management of potato late blight caused by Phytophthora infestans

\begin{tabular}{|c|c|c|c|c|c|}
\hline Site & Abbreviation & Altitude $^{\mathrm{a}}$ & Planting dates & $\begin{array}{l}\text { Number of disease evaluations } \\
\text { (evaluation period) }\end{array}$ & Harvest dates \\
\hline Estación Santa Catalina 1997 & ESC97 & 3,060 & 22 and 27 Nov 1996 & 5 (7 Feb - 17 Mar 1997) & 15-17 Apr 1997 \\
\hline Estación Santa Catalina 1998 & ESC98 & 3,060 & 12-13 Jan 1998 & 5 (20 Feb - 31 Mar 1998) & 23-30 Apr 1998 \\
\hline $\begin{array}{l}\text { Instituto Andino Superior } \\
\text { de Agropecuaria }\end{array}$ & IASA98 & 2,700 & 3-4 Feb 1998 & 6 (9 Apr - 7 May 1998) & 24-25 Jun 1998 \\
\hline $\begin{array}{l}\text { Centro Académico Docente } \\
\text { Experimental La Tola }\end{array}$ & CADET98 & 2,500 & 12-13 Jan 1998 & 7 (6 Mar - 17 Apr 1998) & 17-18 Jun 1998 \\
\hline
\end{tabular}

${ }^{a}$ Meters above sea level.

TABLE 2. Treatments included in a study of the effects of host diversity and other disease management practices on potato late blight caused by Phytophthora infestans

\begin{tabular}{|c|c|c|c|c|}
\hline Treatment $^{\mathrm{a}}$ & Density & Fungicide $^{b}$ & Genotype & Expectation under null hypothesis $\left(H_{o}\right)^{\mathrm{c}}$ \\
\hline $\mathrm{T} 1$ & Standard & None & Santa Catalina (SC) (resistant) & $\ldots$ \\
\hline $\mathrm{T} 2$ & Standard & None & Gabriela (GA) (moderately resistant) & $\ldots$ \\
\hline T3 & Standard & None & Cecilia (CE) (susceptible) & $\ldots$ \\
\hline $\mathrm{T} 4$ & Standard & None & Uvilla (UV) (susceptible) & $\ldots$ \\
\hline T5 & Standard & None & $3 / 4 \mathrm{SC}$ and $1 / 4 \mathrm{UV}$ & $3 / 4 \mathrm{~T} 1+1 / 4 \mathrm{~T} 4$ \\
\hline T6 & Standard & None & $1 / 3 \mathrm{SC}, 1 / 3 \mathrm{GA}$, and $1 / 3 \mathrm{CE}$ & $1 / 3 \mathrm{~T} 1+1 / 3 \mathrm{~T} 2+1 / 3 \mathrm{~T} 3$ \\
\hline $\mathrm{T} 7$ & Standard & None & $1 / 3 \mathrm{SC}, 1 / 3 \mathrm{CE}$, and 1/3 UV & $1 / 3 \mathrm{~T} 1+1 / 3 \mathrm{~T} 3+1 / 3 \mathrm{~T} 4$ \\
\hline $\mathrm{T} 8$ & Standard & None & 1/10 SC and $9 / 10$ faba beans & $\mathrm{T} 1$ \\
\hline Т9 & Standard & None & $1 / 10 \mathrm{GA}$ and $9 / 10$ faba beans & $\mathrm{T} 2$ \\
\hline T10 & Standard & None & 1/10 CE and $9 / 10$ faba beans & $\mathrm{T} 3$ \\
\hline $\mathrm{T} 11$ & Standard & None & $1 / 10 \mathrm{UV}$ and $9 / 10$ faba beans & $\mathrm{T} 4$ \\
\hline $\mathrm{T} 12$ & High & None & $\mathrm{SC}$ & $\mathrm{T} 1\left(H_{\mathrm{o}}:\right.$ no density effect $)$ \\
\hline T13 & High & None & UV & $\mathrm{T} 4\left(H_{\mathrm{o}}\right.$ : no density effect $)$ \\
\hline T14 & High & None & $3 / 4 \mathrm{SC}$ and $1 / 4 \mathrm{UV}$ & $3 / 4 \mathrm{~T} 12+1 / 4 \mathrm{~T} 13$ \\
\hline $\mathrm{T} 15$ & Standard & Biweekly & $\mathrm{SC}$ & $\mathrm{T} 1\left(H_{\mathrm{o}}\right.$ : no fungicide effect) \\
\hline T16 & Standard & Biweekly & UV & $\mathrm{T} 4\left(H_{\mathrm{o}}\right.$ : no fungicide effect) \\
\hline T17 & Standard & Biweekly & $3 / 4 \mathrm{SC}$ and $1 / 4 \mathrm{UV}$ & $3 / 4 \mathrm{~T} 15+1 / 4 \mathrm{~T} 16$ \\
\hline T18 & Standard & Weekly & $\mathrm{SC}$ & $\mathrm{T} 1\left(H_{\mathrm{o}}\right.$ : no fungicide effect $)$ \\
\hline T19 & Standard & Weekly & UV & $\mathrm{T} 4\left(H_{\mathrm{o}}\right.$ : no fungicide effect) \\
\hline $\mathrm{T} 20$ & Standard & Weekly & $3 / 4 \mathrm{SC}$ and $1 / 4 \mathrm{UV}$ & $3 / 4 \mathrm{~T} 18+1 / 4 \mathrm{~T} 19$ \\
\hline
\end{tabular}

a Only treatments 1 to 4 and 6 to 11 were applied at site-year ESC97.

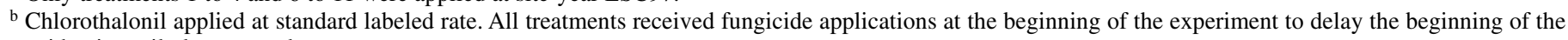
epidemic until plants were larger.

c The null hypothesis being considered is that there was no host-diversity effect, unless otherwise indicated. 
calculated by the midpoint rule method (2), was used as one response variable:

$$
\mathrm{AUDPC}_{i j}=\sum_{k=1}^{n-1}\left[\left(t_{k+1}-t_{k}\right)\left(y_{i j k}+y_{i j(k+1)}\right) / 2\right]
$$

where $y_{i j k}$ is the percent severity observed for the $k$ th observation date of the $i$ th treatment in the jth block, $t_{k}$ is the Julian date of the observation, and observations were made on $n$ dates.

Studies of the effects of host diversity on disease generally involve comparisons of disease severity in a host mixture to the mean disease severity in the same host genotypes growing in singlegenotype stands. It is often useful to consider both the absolute difference in severity between mixtures and single-genotype stands and the relative difference in severity. For the comparison of the relative difference, we used what we termed the relative mixture response (RMR): AUDPC in mixture/weighted mean AUDPC in single-genotype stands. The RMR allows for comparisons between host-diversity effects in settings that may have very different overall levels of disease, such as different fungicide regimes.

We also used a truncated formulation of the AUDPC, based on the following rationale. Once one component of a mixture approaches $100 \%$ diseased tissue, a host-diversity effect for that component is no longer possible. Even before $100 \%$ infection is reached, there may be a tendency for disease progress to slow greatly as it approaches its maximum. If the host-diversity effect is expressed as an RMR, this ratio will be pushed toward 1 if measurements of percent diseased tissue continue beyond the point when disease severity of one component is nearly maximum. To allow for comparisons without this effect, a truncated AUDPC (TAUDPC) was also calculated, based on the AUDPC only up to the point when the most susceptible component reached $90 \%$ infection in single-genotype stands. For some mixtures this never occurred, therefore, the TAUDPC was the same as the complete AUDPC.

Truncation to standardize AUDPCs for comparison. To produce the TAUDPC, each measure of percent severity was adjusted as follows. Let $d_{\max }=90$ be the cut-off disease level, the level of disease in the most susceptible component that signals the time for truncation, $t_{m j}{ }^{\max }$, in which we designate the most susceptible component as treatment $m$ in block $j$. Because percent severity was measured only at approximately weekly intervals, $d_{\max }$ was likely to be reached at a time between observation dates. Just as typical calculations of an AUDPC rely on linear interpolation between sampling dates (2), $t_{m j}{ }^{\max }$ was calculated by interpolation between sampling dates in the susceptible variety. Suppose observation date $\mathrm{a}$ is the last observation date at which the percent severity in the most susceptible component is below $d_{\max }$. We first calculated the slope for the most susceptible component, $s_{m j}=$ $\left(y_{m j(a+1)}-y_{m j a}\right) /\left(t_{a+1}-t_{a}\right)$ and then $t_{m j}{ }^{\max }=t_{a}+\left(d_{\max }-y_{m j a}\right) / s_{m j}$. The value of $t_{m j}{ }^{\text {max }}$ calculated from the single-genotype stand of the most susceptible component was used for calculating the TAUDPC for each component and for the corresponding mixture, with calculations done separately for each block so that observations from replicates of a given treatment were independent $(6,12)$. The individual plot slope, $s_{i j}$, between $t_{a}$ and $t_{a+1}$ was calculated separately for each component and for the mixture:

$$
\begin{gathered}
\text { TAUDPC }_{i j}=\sum_{k=1}^{a-1}\left[\left(t_{k+1}-t_{k}\right)\left(y_{i j k}+y_{i j(k+1)}\right) / 2\right]+ \\
\left\{\left(t_{m j}{ }^{\max }-t_{a}\right)\left[2 y_{i j a}+s_{i j}\left(t_{m j}{ }^{\max }-t_{a}\right)\right]\right\} / 2
\end{gathered}
$$

For absolute comparisons, TAUDPC ${ }_{i j}$ was standardized by division by $t_{m j}{ }^{\max }-t_{1}$ and some treatments were analyzed separately to avoid the issue of different truncation times for the same singlegenotype plot when more than one mixture contained that genotype.

Statistical analysis of AUDPC, TAUDPC, and RMR. An analysis of variance (ANOVA) was performed in SAS (SAS Institute Inc., Cary, NC), taking each treatment combination as a different level of a single treatment to make the formulation of tests clearer (Table 2). The following linear model was fit to the data for each site-year combination: $x_{i j}=\mu+\tau_{i}+\beta_{j}+\varepsilon_{i j}$, where $x_{i j}$ is the AUDPC or TAUDPC for the $i j$ th experimental plot, $\tau_{i}$ is the effect of the $i$ th treatment $(i=1, \ldots, 20), \beta_{j}$ is the effect of the $j$ th block $(j=1, \ldots, 4)$, and $\varepsilon_{i j}$ is the residual error. Planned contrasts were used to test effects on the AUDPC and TAUDPC as $c^{\prime} \tau$, where $\tau$ is the vector of treatment effects in the order of Table 2 and $c$ is the vector of coefficients for a particular contrast.

Similarly, for the RMR the following model was fit: $y_{i j}=\mu+\tau_{i}+$ $\varepsilon_{i j}$, where $y_{i j}$ is the RMR for the $i j$ th experimental plot, $\tau_{i}$ is the effect of the $i$ th treatment $(i=5, \ldots, 11,14,17,20)$, and $\varepsilon_{i j}$ is the residual error. Blocks were not included in the RMR model because a block term would represent an interaction between host-diversity effect and block. For analyses of AUDPC, TAUDPC, and RMR, the distribution of residuals from analyses was satisfactory for meeting the distributional assumptions of the ANOVA.

Evaluation of treatment effects. The linear contrasts used to test for treatment main effects are comparisons of observations to the prediction under the null hypothesis of no treatment effect as outlined in the last column of Table 2. The linear contrasts used to test for treatment interactions are outlined in Table 3.

The RMR for intercrops was also considered for faba intercrops separately: $y_{i j} / y_{(i-7) j}=\mu+\tau_{i}+\beta_{j}+\varepsilon_{i j}$, for $i=8,9,10,11$. In this analysis, if $\mu$ is significantly different from 1 this means that there is evidence for an overall effect of intercropping on late blight severity. There is evidence for different effects of intercropping for the different potato cultivars if the $\tau_{i}$ are significantly different from 0 .

For the analysis of the RMR, a host-diversity effect could be detected if the RMR was significantly different from 1 . Note that, for example, tests of a host-diversity effect for mixtures in T5 through T8 are not independent from each other because they all contain estimates from $\mathrm{T} 1$ in their denominator. For tests of the influence of density and fungicide use, there is no problem of dependence because separate single-genotype stands were included to correspond to each density and level of fungicide application.

TABLE 3. Additional planned contrasts used to test hypotheses about management components for potato late blight caused by Phytophthora infestans

\begin{tabular}{ll}
\hline Tests with AUDPC or TAUDPC as response variable $\mathrm{a}^{\mathrm{a}}$ & \multicolumn{1}{c}{ Contrast $^{\mathrm{b}}$} \\
\hline$H_{\mathrm{o}}$ : No overall linear part of fungicide main effect & $-\tau_{1}-\tau_{4}+\tau_{18}+\tau_{19}$ \\
$H_{\mathrm{o}}$ : No overall quadratic part of fungicide main effect & $+\tau_{1}+\tau_{4}-2 \tau_{15}-2 \tau_{16}+\tau_{18}+\tau_{19}$ \\
$H_{\mathrm{o}}$ : No influence of planting density on host-diversity effect & $\left(\tau_{14}-3 / 4 \tau_{12}-1 / 4 \tau_{13}\right)-\left(\tau_{5}-3 / 4 \tau_{1}-1 / 4 \tau_{4}\right)$ \\
$H_{\mathrm{o}}$ : No influence of biweekly fungicide use on host-diversity effect & $\left(\tau_{17}-3 / 4 \tau_{15}-1 / 4 \tau_{16}\right)-\left(\tau_{5}-3 / 4 \tau_{1}-1 / 4 \tau_{4}\right)$ \\
$H_{\mathrm{o}}$ : No influence of weekly fungicide use on host-diversity effect & $\left(\tau_{20}-3 / 4 \tau_{18}-1 / 4 \tau_{19}\right)-\left(\tau_{5}-3 / 4 \tau_{1}-1 / 4 \tau_{4}\right)$ \\
Tests with relative mixture response as response variable & \\
$H_{\mathrm{o}}$ : No influence of host density on host-diversity effect & $\tau_{14}-\tau_{5}$ \\
$H_{\mathrm{o}}$ : No linear part of influence of fungicide use on host-diversity effect & $-\tau_{5}+\tau_{20}$ \\
$H_{\mathrm{o}}$ : No quadratic part of influence of fungicide use on host-diversity effect & $+\tau_{5}-2 \tau_{17}+\tau_{20}$ \\
\hline
\end{tabular}

${ }^{a}$ AUDPC $=$ area under disease progress curve; and TAUDPC $=$ truncated AUDPC.

${ }^{b}$ Treatment numbers refer to the treatments as listed in Table 2. 
Yield. Fresh weights of tubers were recorded for all rows of each plot on the dates indicated in Table 1. Yield from faba intercrops was not analyzed because of the difficulties of interpretation given the small number of potato plants and the poor stands of fabas. The same set of linear contrasts as used for disease was used to compare treatment effects on yield. Because there was a tendency for the variance of residuals to increase with increased predicted values, the analysis was adjusted to allow for different variances for different treatments. SAS Proc Mixed was used to perform the analysis, including the statement, repeated/group $=$ trt, as in Garrett and Mundt (12), where trt indicates the treatments as listed in Table 2.

Analysis of IPM components across sites. Treatments from the three sites in 1997-98 that allowed the most direct comparison were evaluated to summarize the performance of the different management techniques. Responses were expressed as the percent reduction in the AUDPC, TAUDPC, and yield. We constructed comparisons of how well a particular treatment performed compared with plots without the benefit of that treatment (Table 4). Because we only had three data points for each analysis at this spatial scale, we did not perform a statistical analysis.

\section{RESULTS}

Foliar late blight severity on a site-by-site basis: single-genotype stands. The relative levels of resistance of potato cultivars in single-genotype stands were generally as expected, though there was some variation from site to site. 'Gabriela' had intermediate levels of disease in ESC98 and CADET98. At the other sites in 1998-99, 'Gabriela' performed similarly to highly susceptible cv. Uvilla (Fig. 1). 'Cecilia' had less disease than 'Uvilla' at CADET98, although the two cultivars were similar in disease expression for other site-years (Fig. 1).

Mixtures with varying resistance levels. A host-diversity effect for reduced AUDPC without fungicide use was evident only at site CADET98 (Fig. 2). The largest estimated host-diversity effect was for the 3/4 'Santa Catalina' + 1/4 'Uvilla' mixture with weekly fungicide applications. There was a trend toward hostdiversity effects when considering all the site-year combinations, and this trend was more striking for the analysis with the TAUDPC (Fig. 2).

Faba intercropping. Faba plants had poor emergence in the 1996-97 season and were generally smaller and sparser than potato plants at all sites in the 1997-98 season as well. When cul- tivars were analyzed individually by linear contrasts, there was only weak evidence for potato-faba intercropping effects $(P>0.11$ in all cases), although there was a clear trend toward reduced late blight in intercrops compared with single-genotype stands (Fig. 3). Similarly, for the analysis of the RMR in faba intercrops for each cultivar separately, there was no evidence for differences in effects for different cultivars. When the overall effect of intercropping was tested for each site (combining cultivars), the trend toward reduced disease in intercrops was reflected in some statistical evidence for this overall intercrop effect, though only for ESC98 (RMR based on AUDPC, $P=0.10$; RMR based on TAUDPC, $P<0.01$ ), IASA (RMR-AUDPC, $P=0.01$; RMRTAUDPC, $P<0.01$ ), and CADET98 (RMR-TAUDPC, $P<0.01$ ).

Density treatments. In single-genotype plots of cvs. Santa Catalina and Uvilla, the AUDPC was lower at the standard planting density than at the doubled planting density at each of the three sites (Fig. 4). However, this trend was not statistically significant at any of the three sites for linear contrasts on the AUDPC $(P>0.20$ in all cases). For mixtures at the higher planting density, there was weak evidence for a host-diversity effect from linear contrasts on the AUDPC only at site CADET98 $(P=0.09)$ (Fig. 2).

Fungicide treatments. Fungicide applications reduced late blight severity in single-genotype stands for both weekly and biweekly treatments at all sites $(P<0.01$ for all tests). In singlegenotype stands, there was also a strong trend toward lower percent severity for weekly application of fungicides compared with biweekly application. There was strong statistical evidence for this trend in linear contrasts on the AUDPC for both 'Santa Catalina' $(P<0.01)$ and 'Uvilla' $(P<0.01)$ at IASA98, for neither cultivar at ESC98 $(P>0.15$ for both $)$, and only for 'Uvilla' $(P=0.05)$ at CADET98.

There was also strong evidence for increased host-diversity effects with increasing fungicide application levels. This effect was highly significant for the test of a linear effect of fungicide application on host-diversity effects on the RMR calculated from the AUDPC $(P<0.01$ for all sites). Results varied for other forms of tests of the interaction between fungicides and host-diversity effects. For linear contrasts on the AUDPC, there was evidence supporting the linear part of the fungicide effect on host-diversity effects only at ESC98 $(P=0.06)$, and there was little evidence supporting the quadratic part at any site $(P>0.2)$. There was evidence supporting the quadratic effect of fungicide application on host-diversity effects on the RMR calculated from the AUDPC only at IASA98 $(P<0.01)$. Results were similar for an RMR

TABLE 4. Effectiveness of disease management practices and their combinations on potato late blight caused by Phytophthora infestans based on responses for three research sites

\begin{tabular}{|c|c|c|c|c|c|c|c|c|c|}
\hline \multirow[b]{3}{*}{ Components } & \multicolumn{6}{|c|}{$\%$ Change in disease levels due to components ${ }^{\mathrm{a}}$} & & & \\
\hline & \multicolumn{3}{|c|}{ Based on AUDPC ${ }^{b}$} & \multicolumn{3}{|c|}{ Based on TAUDPC ${ }^{b}$} & \multicolumn{3}{|c|}{$\%$ Change in yield due to components } \\
\hline & Mean & Best site & Worst site & Mean & Best site & Worst site & Mean & Best site & Worst site \\
\hline Resistance $^{c}$ & -53 & -72 & -35 & $\ldots$ & $\ldots$ & $\ldots$ & +158 & +236 & +76 \\
\hline Fungicides ${ }^{\mathrm{d}}$ & -45 & -63 & -34 & $\ldots$ & $\ldots$ & $\ldots$ & +441 & $+1,142$ & +76 \\
\hline Density & -3 & -4 & -2 & $\ldots$ & $\ldots$ & $\ldots$ & -2 & 0 & -3 \\
\hline Intercropping & -5 & -8 & -2 & -10 & -18 & -4 & $\mathrm{NA}^{\mathrm{f}}$ & NA & NA \\
\hline Host diversity ${ }^{\mathrm{g}}$ & -4 & -23 & +14 & -25 & -62 & -2 & -3 & +27 & -19 \\
\hline Resistance + fungicides ${ }^{\mathrm{h}}$ & -91 & -96 & -85 & $\ldots$ & $\ldots$ & $\ldots$ & $+4,026$ & $+11,167$ & +359 \\
\hline Host diversity + fungicides ${ }^{i}$ & -75 & -86 & -56 & $\ldots$ & $\ldots$ & $\ldots$ & +187 & +298 & +128 \\
\hline Host diversity + density ${ }^{j}$ & -18 & -32 & +12 & $\ldots$ & $\ldots$ & $\ldots$ & -11 & +12 & -29 \\
\hline
\end{tabular}

a Table entries are $[($ mean observation - mean prediction under null hypothesis of no effect $) /($ mean prediction under null hypothesis of no effect $)] \times 100$.

${ }^{\mathrm{b}} \mathrm{AUDPC}=$ area under disease progress curve; and TAUDPC $=$ truncated AUDPC.

c 'Santa Catalina' (resistant) versus 'Uvilla' (susceptible).

d 'Uvilla' with weekly fungicide applications versus 'Uvilla' with no fungicide applications.

e 'Uvilla' at standard density versus 'Uvilla' at high density.

${ }_{\mathrm{f}}$ Not available. Potato yield analyses for the potato-faba intercrops were inappropriate because of the poor faba stands.

$\mathrm{g}$ 'Uvilla' and 'Santa Catalina' in mixture versus weighted mean of single-genotype stands.

h 'Santa Catalina' with weekly fungicide applications versus 'Uvilla' with no fungicide applications.

i 'Uvilla' and 'Santa Catalina' in mixture with weekly fungicide applications versus weighted mean of single genotype stands with no fungicide applications.

$\mathrm{j}$ 'Uvilla' and 'Santa Catalina' in mixtures at standard density versus weighted mean of single-genotype stands at high density. 
based on the TAUDPC, but there was evidence for a quadratic rather than linear effect of fungicide application on host-diversity effects at CADET98 (linear $P=0.35$, quadratic $P=0.01$ ).

Yield on a site-by-site basis. There was evidence for a hostdiversity effect on yield only for the $1 / 3$ 'Santa Catalina' $+1 / 3$ 'Gabriela' + 1/3 'Cecilia' mixture. This evidence was for increased yield at ESC97 $(P=0.09)$ and CADET98 $(P=0.07)$, but there was no evidence for an effect at ESC98 $(P=0.43)$ or IASA98 $(P=0.56)$. There was little statistical support for an effect of density on yield in single-genotype stands or for a density effect on the host-diversity effect on yield ( $P>0.25$ for all tests). Effects of a weekly fungicide spray on yield of single-genotype stands of 'Santa Catalina' were at least marginally significant at all sites $(P<0.11)$. There was less consistent evidence for an effect of a biweekly fungicide regime. There was no evidence that the type or lack of a fungicide regime influenced the magnitude of a hostdiversity effect on yield ( $P>0.4$ for all tests).

Effects on foliar late blight severity and yield across sites. The effect of high levels of host resistance on foliar blight severity in cv. Santa Catalina compared with the level of resistance in cv. Uvilla was similar to the effect of a weekly fungicide regime (Table 4). The effects of density and intercropping were small but consistent at all three sites. The effects of host diversity were variable, with an increase in disease in mixtures at one site. The combination of host resistance in cv. Santa Catalina and a weekly fungicide regime was quite successful at reducing disease severity, with consistent results at all sites. Host diversity in combination with fungicides also provided substantial disease control, but the combination of host diversity and density manipulation was less effective.

For yield, the effect of host resistance in cv. Santa Catalina in combination with its other genetic differences from cv. Uvilla provided fairly consistent and substantial benefits. The effect of fungicides on yield was greater, with a particularly large effect at CADET98. Increasing the standard planting density tended to increase yield slightly. The effects of host diversity were variable, with a decrease in yield in mixtures at two sites. The effect of resistant cv. Santa Catalina's genetic differences from cv. Uvilla in combination with fungicide applications greatly increased yield, particularly at the site with the largest fungicide effects. Host diversity in combination with fungicide applications also consistently increased yield. Host diversity combined with the lower (standard) host density provided variable results, tending toward a decrease in yield.

\section{DISCUSSION}

We found evidence for a host-diversity effect on late blight severity, but this effect varied over the three locations of our study and between years (Fig. 2). For ESC, the site where we expected the most inoculum from adjacent fields, host diversity did not reduce disease but, rather, there was some evidence for a hostdiversity effect for increased severity. The largest host-diversity effect for decreased disease severity in mixtures was for potato cv. Uvilla at CADET98, the site most distant from other potato fields. The contrasting results from these two sites are consistent with the idea that the level of outside inoculum is an important factor driving the magnitude of host-diversity effects (23). However, the results for faba intercrops do not show the same clear difference between sites. For these, the estimated effect of intercropping at the isolated site CADET98 was essentially the same in magnitude as for the other site-years. The difference in results for faba intercrops and potato mixtures might be explained by the following factors. First, because of the generally poor growth of fabas in this experiment, they may have provided much less of a physical barrier between potato plants of the same genotype than did potatoes in the potato mixtures. In addition, potatoes in potato mixtures may have been subject to more effects from plant competition and the ways in which competition varied from one site to another. Likewise, there was no possibility of compensation
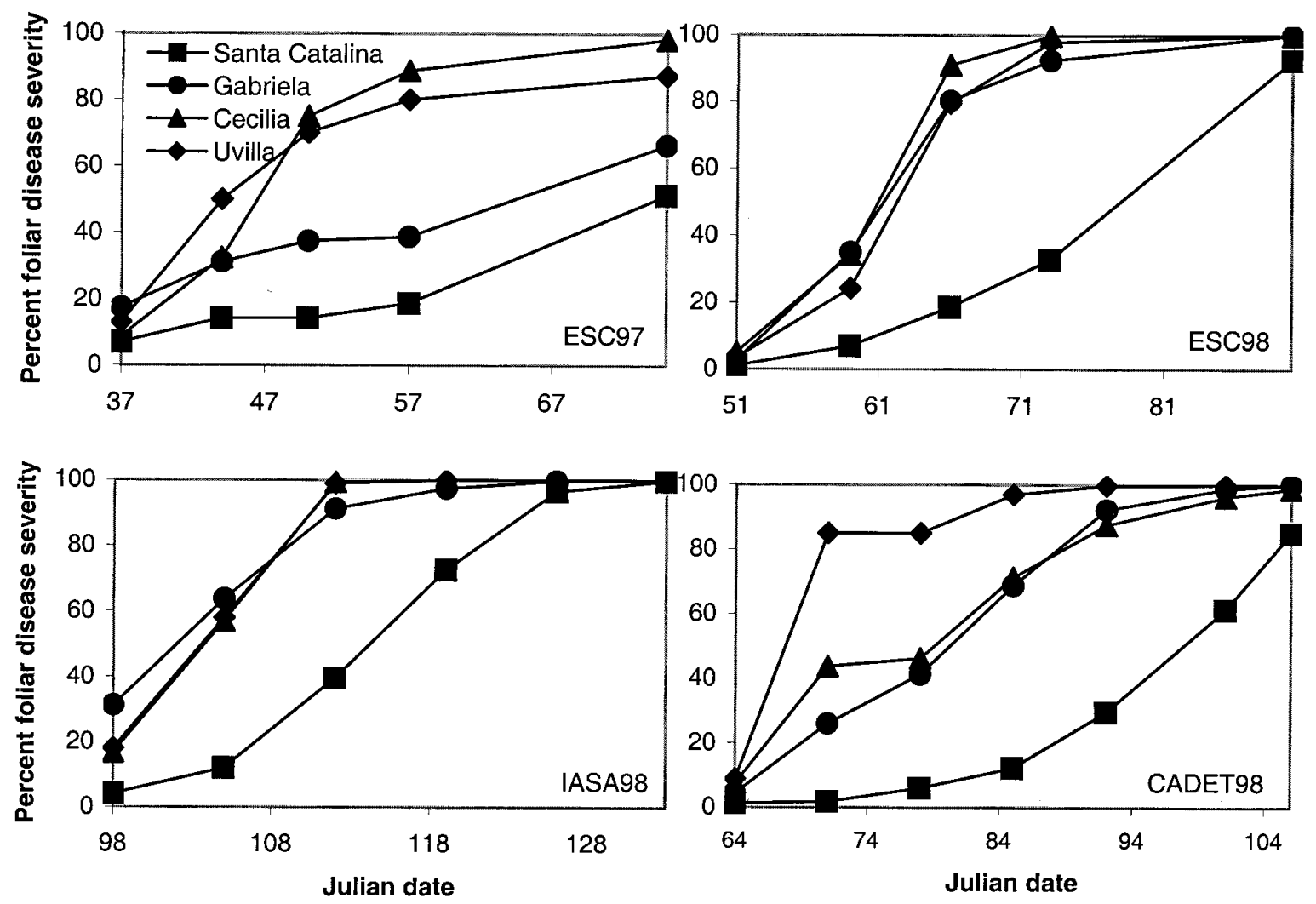

Fig. 1. Disease progress curves for late blight caused by Phytophthora infestans in single-genotype plots of each of the four potato genotypes for the four site-year combinations. 
in intercrops because severity was measured only on potato plants; that is, foliage loss in the susceptible cultivar could not be replaced by growth of the resistant cultivar. Finally, we anticipated greater variance in our estimates of disease severity in intercrop plots, because severity was measured for only four potato plants per plot compared with the 40 plants per plot in a potato mixture.

We might have anticipated that higher density plots would produce a microclimate more conducive to late blight (1). However, several recent studies have found either no effect of density or a negative association between planting density and disease severity $(5,7,12,20)$. One reason that disease may show little response to density changes is that the realized density of foliage may be similar over planting densities (20). Traditional potato cultivars in the Andes, including those we used, are late maturing and produce large amounts of foliage. It might be that a planting density much lower than standard would reduce late blight, but yield might be reduced enough to make such a planting density impractical. In general, we might expect that a higher planting density would produce a greater host-diversity effect because susceptible tissue would appear in smaller areas (10). But, in this experiment, there was no evidence for an influence of planting density on hostdiversity effects, as might be expected because of the small density effects in single-genotype stands. This is in contrast to wheat stripe rust, for which there was a large influence of planting density on host-diversity effects (12). Differences in the influence of density in these two systems may be due in part to differences

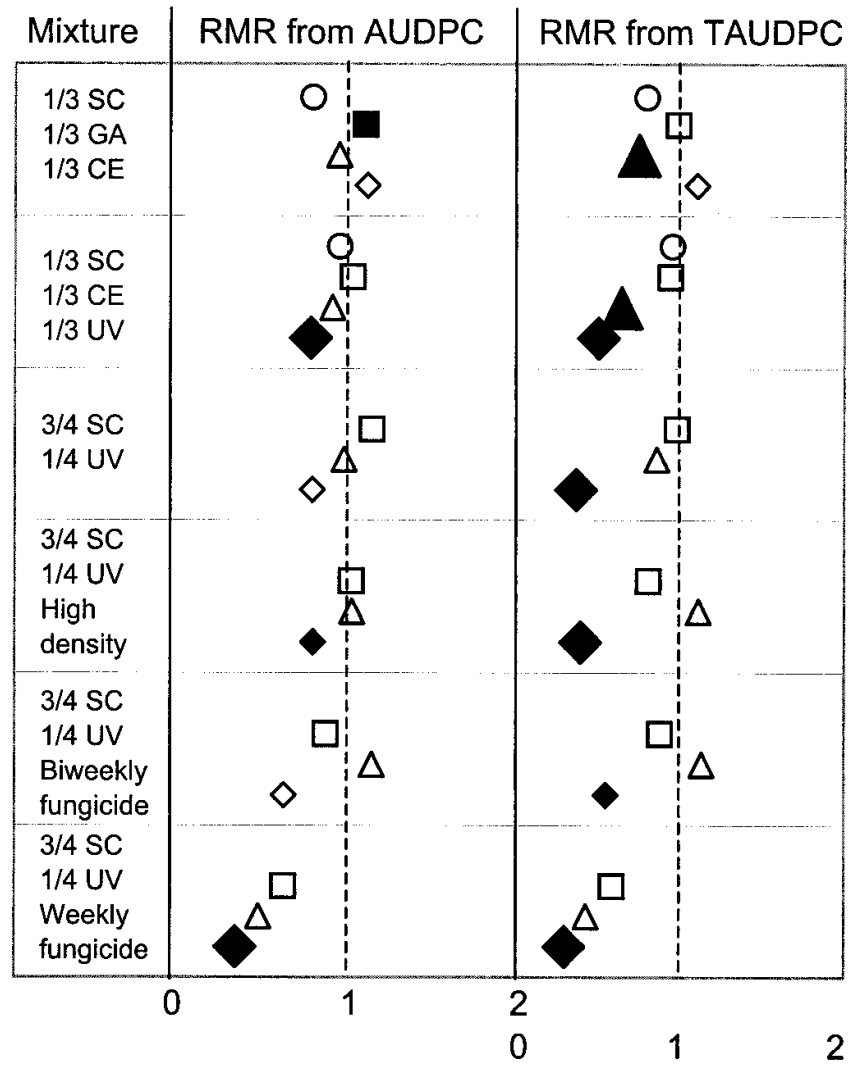

Fig. 2. The relative mixture response (RMR; area under disease progress curve [AUDPC] in mixture per weighted mean AUDPC in single-genotype stands) for potato late blight in three potato mixtures. An RMR less than 1 indicates a host-diversity effect for reduced disease. The mixture of 3/4 'Santa Catalina' (resistant) and 1/4 'Uvilla' (susceptible) was studied at double the standard planting density and under two fungicide regimes. The statistical significance of the host-diversity effect, based on linear contrasts, is indicated by the shading and size of individual symbols. Symbols shaded black indicate $P<0.10$; and enlarged symbols indicate $P<0.05$. Results were also calculated for the same mixtures with RMR calculated using the truncated AUDPC (TAUDPC). Circle = site-year ESC97; square = site-year ESC98; triangle = site IASA98; and diamond = site CADET98. in plant architecture and pathogen dispersal, but it would be useful to consider lower potato densities than were included in this experiment to clarify the comparison.

In general, there was a greater host-diversity effect for plots that received fungicide applications (Fig. 2). This interaction was especially marked at site CADET98. Greater host-diversity effects might be predicted because an epidemic that lasts longer before plants are destroyed by disease, whether because of fungicide applications or other factors such as higher overall disease resistance, would allow time for more pathogen generations (17). This analysis also demonstrates the utility of studying both the absolute (in terms of linear contrasts) and relative (in terms of RMR) hostdiversity effects. For site CADET98, there was little influence of fungicide regime on the absolute host-diversity effect; the absolute reduction in AUDPC due to host diversity was approximately the same regardless of the fungicide regime (data not shown). However, the relative reduction was much greater for plots with weekly fungicide application (Fig. 2).

The analysis at CADET98 illustrates the utility of the TAUDPC. We can interpret the TAUDPC as a measure of the effects of host diversity while the susceptible component of a mixture is still available for infection. If the greater number of pathogen generations during the course of the epidemic resulted in a greater hostdiversity effect for plots with fungicide treatments, we might expect that the RMR based on the TAUDPC would also show a greater effect for fungicide treatments. This was true for two sites, but at site CADET98, the RMR based on the TAUDPC was essentially the same whether or not fungicide was applied (Fig. 2). Although the epidemic in the susceptible genotype was still active, the host-diversity effect seemed to be just as great with or without fungicide applications at this site. The difference under a

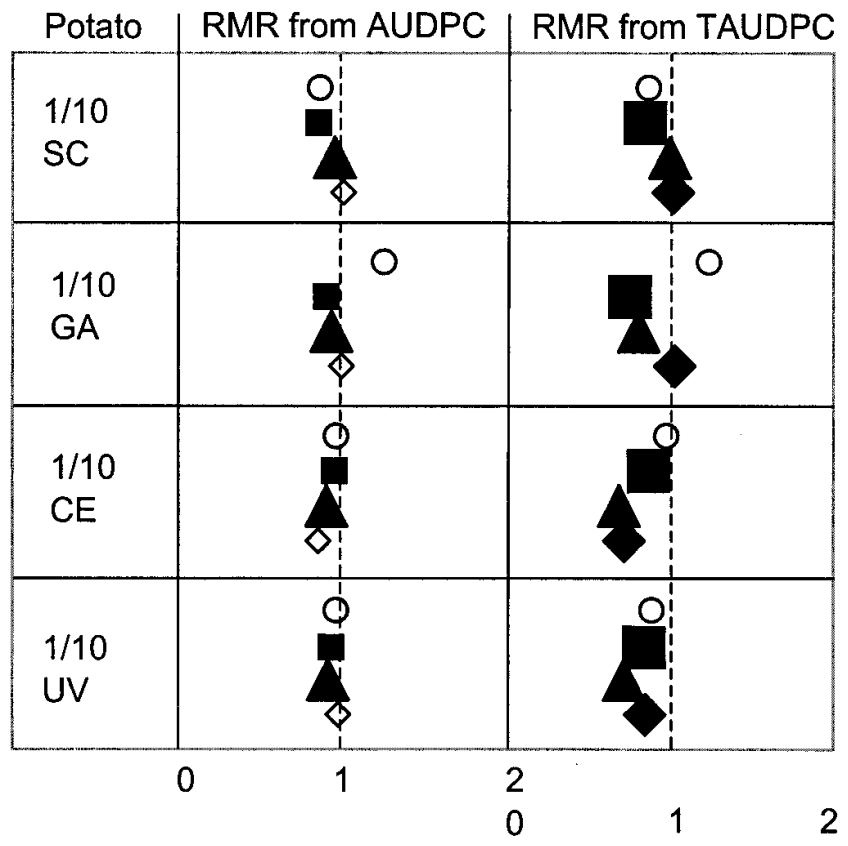

Fig. 3. The relative mixture response (RMR; area under disease progress curve [AUDPC] in mixture per weighted mean AUDPC in single-genotype stands) for potato late blight in four potato cultivars in separate intercrops with faba bean. An RMR less than 1 indicates that there was an effect from intercropping for reducing disease. Because no effects were significant in tests based on individual cultivars, significance levels for tests of an overall intercropping effect based on the RMR for all faba intercrops at a site are illustrated. Symbols shaded black indicate $P<0.10$ for the overall intercropping test; and enlarged symbols indicate $P<0.05$ for the overall intercropping test. Results were also calculated for the same intercrops with the RMR calculated using the truncated AUDPC (TAUDPC). Circle = site-year ESC97; square = site-year ESC98; triangle = site IASA98; and diamond = site CADET98. 
fungicide regime was that the epidemic was slowed so that apparently the susceptible component could benefit from mixture with the resistant component throughout the season. It could also be that, while the host-diversity effect was compounding in the fungicide-treated plots over time, the levels of outside inoculum and inoculum from neighboring plots were also increasing over time.

Host-diversity effects on yield were greatest, on average, at site CADET98, with the most important host-diversity effect being for the mixtures with weekly fungicide applications at that site (Table 4). This is consistent with the fact that we observed the greatest host-diversity effect on disease severity for that treatment. For treatments that had small or no host-diversity effects on disease severity, there was no reason to expect a large host-diversity effect on yield. The potato cultivars selected for this study were chosen based only on our knowledge of their levels of resistance and would not necessarily be compatible in other aspects of their cultivation.

In comparing the effect of the individual IPM components on late blight severity, genetic resistance and fungicide applications were clearly the most important (Table 4). Their effects were similar, though we should note that fungicide applications were included at the beginning of the season for all treatments. The approximate equality in contribution between fungicides and resistance is similar to the results of Fry's (9) study of fungicides and resistance in the United States. Both density manipulation and intercropping provided only small effects, but their cumulative effects over many seasons could be important. On average, host diversity alone gave a small reduction in disease severity, but with variable effects. The effects of host diversity measured by the TAUDPC were generally larger. If we interpret the TAUDPC as giving results more similar to what might be seen for a successful mixture with higher overall levels of resistance, this suggests that host diversity could become a more important management component as the overall level of resistance for potential mixture components increases.

The combination of resistance and fungicide applications reduced disease levels greatly (Table 4). In the Quito area, where tuber blight is generally not found (G. A. Forbes, personal observation), a $91 \%$ reduction in AUDPC may be adequate. The combination of host diversity and density manipulation was not effective enough for reliable management without other management components. The combination of host diversity and fungicides was more promising than host diversity alone, though better direct tests for interactions between management components are given by the contrasts in Table 3. With very few exceptions (14), this combination of management techniques has not been examined. If the usefulness of this combination is due at least in part to the fact that more pathogen generations can occur during the longer epidemic produced by fungicides, then a similar effect might be anticipated if the overall level of resistance was increased within a genotype mixture. It would be useful to compare the hostdiversity effect in two mixtures, both with the same magnitude of difference in resistance between components, but with different overall levels of resistance. We might anticipate that the hostdiversity effect would be greater for the higher overall level of resistance.

In comparing the effect of the different IPM components on yield, resistance and fungicide regimes were again clearly the most important (Table 4). Higher densities tended to produce slightly higher yields. Host diversity produced variable responses; it might be expected that its effect on yield would be even more variable than its effect on disease severity, because the mixture components were not selected to optimize yield. The combination of resistance and fungicides was very important for increasing yield, particularly at one site where susceptible cv. Uvilla failed almost completely in single-genotype stands without fungicide applications. The combination of fungicides and host diversity showed some promise, though, again, the mixture components would need to be selected on multiple criteria to boost the efficiency of this combination.

This study illustrates the importance of studying the effects of host diversity and other potential IPM components in a range of environments; if any one of these sites had been the sole study site, very different conclusions might have been drawn. Studies over a longer period of time would also allow consideration of how host diversity might influence pathogen evolution. Probably the current use of potato genotype mixtures by small farmers gives some cumulative benefit for management of late blight over seasons and locales, in addition to general bet-hedging for other agronomic features, although in any given season and locale the effects may be variable. To the extent that high levels of outside inoculum may reduce the efficacy of host diversity for disease
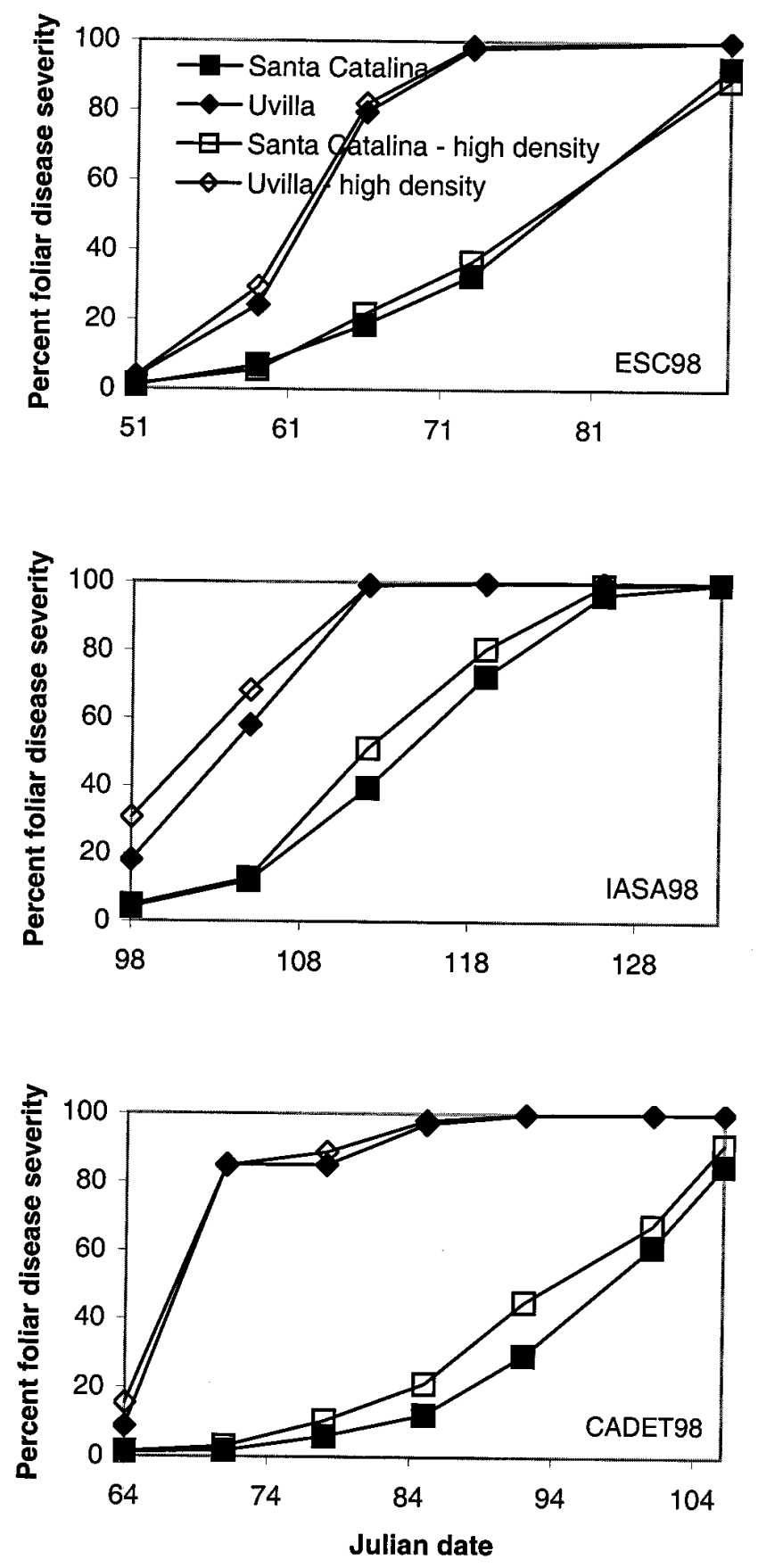

Fig. 4. Disease progress curves for late blight in single-genotype plots of potato cvs. Santa Catalina and Uvilla at standard and high planting densities. 
management, this constraint might be removed as regional management of late blight improves; a landscape-scale study examining the role of specific infection sources, such as that of Zwankhuizen et al. (24), would help to clarify these interactions.

We can consider improvements in the efficacy of host diversity for disease management in terms of selecting components with better differential resistance and also in terms of selecting true potato seed parents for useful diversity in resistance genes. One of the challenges for developing good differential mixtures for late blight management in Ecuador is the apparent high degree of specific virulence in the absence of selection (8). The cost of virulence in $P$. infestans may be low or negligible. However, if sexual reproduction of $P$. infestans occurs on a large scale in the future, mixtures with major genes for resistance might play a larger role. Race-nonspecific adaptation may be of use: Oyarzun et al. (19) found different levels of aggressiveness of isolates from potatoes and tomatoes when infecting potato. Race-nonspecific adaptation to host genotype may be important in partitioning pathogen populations in host mixtures $(3,15,16,18)$.

To summarize, we found a host-diversity effect on potato late blight at one of three research sites near Quito, Ecuador. This site was the lowest (and therefore warmest), driest, and we assume most free from outside inoculum. In that sense, this site is more similar to those in the temperate zone where host diversity has had a more consistent suppressive effect on late blight development (D. Andrivon, personal communication; 11). At the other sites with higher altitude, which are more typical of potato production in the humid tropical highlands, there was evidence, although weak, that host diversity can enhance the disease suppressive effects of fungicides. Future research should explore the potential use of host diversity in combination with other practices designed to slow epidemic rate, including fungicides, host resistance, and planting at higher altitudes where temperatures are lower.

\section{ACKNOWLEDGMENTS}

This research was funded in part by USAID linkage funds. We thank C. Cañizares for management of the experiment at CADET and the Forbes family for making work at Quito such a pleasure.

\section{LITERATURE CITED}

1. Burdon, J. J., and Chilvers, G. A. 1982. Host density as a factor in plant disease ecology. Annu. Rev. Phytopathol. 20:143-166.

2. Campbell, C. L., and Madden, L. V. 1990. Introduction to Plant Disease Epidemiology. Wiley-Interscience, New York.

3. Chin, K. M., and Wolfe, M. S. 1984. Selection on Erysiphe graminis in pure and mixed stands of barley. Plant Pathol. 33:535-546.

4. Crissman, C. C., Espinosa, P., Ducrot, C. E. H., Cole, D. C., and Carpio, F. 1998. The case study site: Physical health and potato farming systems in Carchi province. Pages 85-120 in: Economic, Environmental, and Health Tradeoffs in Agriculture: Pesticides and the Sustainability of Andean Potato Production. C. C. Crissman, J. M. Antle, and S. M. Capalbo, eds. Kluwer Academic, Dordrecht, the Netherlands.
5. Dill-Macky, R., and Roelfs, A. P. 2000. The effect of stand density on the development of Puccinia graminis f. sp. tritici in barley. Plant Dis. 84:29-34.

6. Federer, W. T. 1993. Statistical Design and Analysis for Intercropping Experiments. Vol. 1. Two Crops. Springer-Verlag, New York.

7. Finckh, M. R., Gacek, E. S., Czembor, H. J., and Wolfe, M. S. 1999. Host frequency and density effects on powdery mildew and yield in mixtures of barley cultivars. Plant Pathol. 48:807-816.

8. Forbes, G. A., Escobar, X. C., Ayala, C. C., Revelo, J., Ordoñez, M. E., Fry, B. A., Doucett, K., and Fry, W. E. 1997. Population genetic structure of Phytophthora infestans in Ecuador. Phytopathology 87:375-380.

9. Fry, W. E. 1978. Quantification of general resistance of potato cultivars and fungicide effects for integrated control of potato late blight. Phytopathology 68:1650-1655.

10. Garrett, K. A., and Mundt, C. C. 1999. Epidemiology in mixed host populations. Phytopathology 89:984-990.

11. Garrett, K. A., and Mundt, C. C. 2000. Host diversity can reduce potato late blight severity for focal and general patterns of primary inoculum. Phytopathology 90:1307-1312.

12. Garrett, K. A., and Mundt, C. C. 2000. Effects of planting density and the composition of wheat cultivar mixtures on stripe rust: An analysis taking into account limits to the replication of controls. Phytopathology 90:13131321.

13. Hijmans, R. J., Forbes, G. A., and Walker, T. S. 2000. Estimating the global severity of potato late blight with a GIS-linked disease forecaster. Plant Pathol. 49:697-705.

14. Kousik, C. S., Sanders, D. C., and Ritchie, D. F. 1996. Mixed genotypes combined with copper sprays to manage bacterial spot of bell peppers. Phytopathology 86:502-508.

15. Lannou, C., and Mundt, C. C. 1996. Evolution of a pathogen population in host mixtures: Simple race-complex race competition. Plant Pathol. 45:440-453.

16. Lannou, C., and Mundt, C. C. 1997. Evolution of a pathogen population in host mixtures: Rate of emergence of complex races. Theor. Appl. Genet. 94:991-999.

17. Leonard, K. J. 1969. Factors affecting rates of stem rust increase in mixed plantings of susceptible and resistant oat varieties. Phytopathology 59:1845-1850.

18. Mundt, C. C., Cowger, C., and Hoffer, M. E. 1999. Disease management using variety mixtures. Pages 111-116 in: Septoria and Stagonospora Diseases of Cereals: A Compilation of Global Research. M. van Ginkel, A. McNab, and J. Krupinsy, eds. International Maize and Wheat Improvement Center, Mexico, D.F.

19. Oyarzun, P. J., Pozo, A., Ordoñez, M. E., Doucett, K., and Forbes, G. A. 1998. Host specificity of Phytophthora infestans on tomato and potato in Ecuador. Phytopathology 88:265-271.

20. Pfleeger, T. G., and Mundt, C. C. 1998. Wheat leaf rust severity as affected by plant density and species proportion in simple communities of wheat and wild oats. Phytopathology 88:708-714.

21. Rhoades, R. E., and Bebbington, A. J. 1990. Mixing it up: Variations in Andean farmers' rationales for intercropping of potatoes. Field Crops Res. 25:145-156.

22. Urbano, E., Forbes, G., and Ordoñez, M. E. 1994. Efecto del tamaño de parcela en la eficiencia de selección para resistencia a Phytophthora infestans en papa (Solanum tuberosum). Fitopatología 29:137-140.

23. Wolfe, M. S. 1985. The current status and prospects of multiline cultivars and variety mixtures for disease resistance. Annu. Rev. Phytopathol. 23:251-273.

24. Zwankhuizen, M. J., Govers, F., and Zadoks, J. C. 1998. Development of potato late blight epidemics: Disease foci, disease gradients, and infection sources. Phytopathology 88:754-763. 